\title{
Rancang Bangun Sistem Pengontrolan Lampu Rumah Menggunakan Nodemcu
}

\author{
Anton $^{1}$, Era Madona ${ }^{2}$, Nurul Fajria Jaswir ${ }^{3}$ \\ ${ }^{123}$ Jurusan Teknik Elektro Politeknik Negeri Padang \\ anton@pnp.ac.id \\ Kampus Politeknik Negeri Padang, Limau Manis Padang
}

\begin{abstract}
Smartphones are mobile phones that have a high level of capability and provide features that resemble computers. Android is an operating system that is easy to operate and flexible to build or develop its own applications indefinitely. The light controller using the internet is one of the uses of one of the Android operating systems. In this light control control design is used by using a smartphone application that sends data logic 1 (ON) or 0 (OFF) to the thingspeak web server and is read by nodemcu to be sent to the relay. With the existence of a light control system through the internet, it can make it easier for users to turn on and off the lights even if the user is in a place far away from the lamp with delay after the command is run through the android application depending on network speed on the smartphone and password.
\end{abstract}

Keywords: Smartphone, thingspeak, nodemcu, relay

Abstrak - Smartphone merupakan telepon genggam yang mempunyai kemampuan tingkat tinggi dan menyediakan fitur yang menyerupai komputer. Android merupakan salah satu sistem operasi yang mudah dioperasikan dan fleksibel untuk membangun atau mengembangkan aplikasi sendiri secara tidak terbatas. Pengendali lampu menggunakan internet merupakan salah satu pemanfaatan salah satu sistem operasi android. Pada kontrol lampu ini digunakan rancangan kendali dengan menggunakan aplikasi smartphone yang mengirim logika data $1(\mathrm{ON})$ atau O(OFF) ke web server thingspeak dan dibaca oleh nodemcu untuk dikirim ke relay. Dengan adanya sistem pengontrolan lampu melalui internet ini dapat memudahkan pengguna untuk menyalakan dan memadamkan lampu walau pengguna berada di tempat yang jauh dari lampu dengan delay dari setelah perintah dijalankan melalui aplikasi android bergantung pada kecepatan jaringan pada smartphone dan nodemcu.

Kata kunci: Smartphone, thingspeak, nodemcu, relay

(C) 2017 Elektron Jurnal Ilmiah

\section{PENDAHULUAN}

Sebagian besar peralatan yang tercipta untuk keperluan rumah tangga pemakaiannya menggunakan tenaga listrik. Kebutuhan akan tenaga listrik semakin meningkat sementara persediaan pasokan listrik sangat terbatas, hal itu menuntut kita untuk menghemat penggunaan listrik. Lampu rumah merupakan salah satu penyumbang terbesar dalam pemakaian listrik. Penggunaan lampu yang kurang efisien menimbulkan pemborosan listrik yang mengakibatkan tagihan listrik membengkak. Kendali lampu rumah kebanyakan masih menggunakan saklar manual yang terpasang permanen pada masing-masing panel. Pemborosan listrik seringkali disebabkan karena lupa mematikan lampu. Disisi lain perkembangan ponsel pintar dengan sistem operasi android yang mendominasi pasar ponsel dunia semakin banyak tersedia di pasaran dengan harga yang semakin terjangkau. Sistem operasi android sendiri bersifat sistem operasi open source yang dapat dimodifikasi sesuai kebutuhan. Sistem operasi open source yang ada pada ponsel pintar android memungkinkan untuk membuat aplikasi yang dihubungkan dengan rangkaian mikrokontroler dan relay untuk mengendalikan lampu rumah. Menurut AndriSaputra, dkk[1] menjelaskan bahwa pengontrolan lampu dapat dilakukan menggunakan android via bluetooth. Kendali ini maksimal jarak 13 meter. Mikrokontroler yang digunakan adalah arduino uno.(Immanuel Warangkiran dkk,[2] menjelaskan bahwa smartphone dapat digunakan untuk melakukan pengontrolan lampu dengan memanfaatkan wirelss LAN. Lampu yang digunakan adalah sebanyak 3 buah.

Berdasarkan uraian diatas maka penulis mengembangkan system pengontrolan lampu rumah menggunakan mikrokontroler nodemcu. penulis melakukan pengembangan menggunakan nodemcu yang sudah dilengkapi dengan akses wifi dengan memanfaatkan android dan web server thingspeak.com. Tujuan dari penelitian ini merancang dan membuat suatu sistem untuk memudahkan kinerja alat pengontrol lampu rumah dan mengaplikasikan nodemcu pada sistem pengontrolan lampu rumah secara jarak jauh.

\section{METODE PENELITIAN}

Pada bagian ini dijelaskan prosedur perancangan dan pembuatan perangkat yang digunakan dalam pembuatan sistem pengontrolan lampu rumah. 


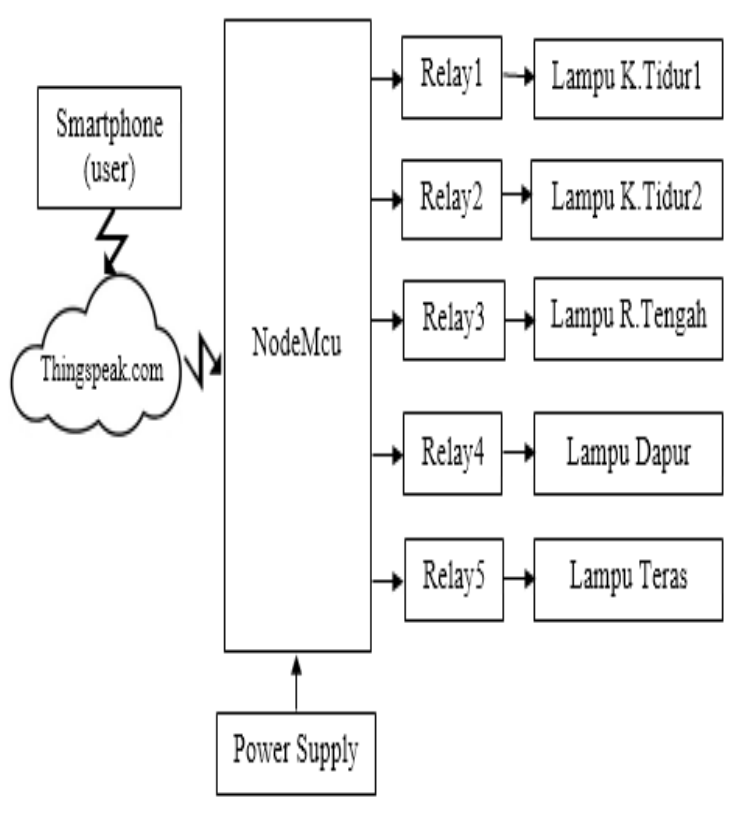

Gambar 1. Blok Diagram Pengontrolan Lampu

Cara kerja sistem kontrol lampu dapat dilihat pada gambar 1. Aplikasi interface yang sudah terinstal pada Smartphone Android mengirimkan data melalui koneksi jaringan internet. Data tersebut berupa data kontrol lampu rumah berlogika $1 / 0$. Ada 10 button pada smartphone yaitu 5 button ON dan 5 button OFF. 5 button ON dan 5 button OFF digunakan untuk pengontrolan 5 buah lampu. Ketika salah satu button ditekan maka data 1/0 akan terkirim ke akun thingspeak yang telah dibuat dan ditampilkan pada grafik. Selanjutnya data $1 / 0$ akan dibaca oleh nodemcu. Nodemcu juga harus terkoneksi jaringan agar dapat membaca data pada thingspeak. Jika data yag terbaca logika 1 maka relay aktif dan lampu ON. Sedangkan jika data yang terbaca oleh nodemcu adalah logika 0 maka relay tidak aktif dan lampu OFF.

\section{B. Perancangan Perangkat Keras}

Perancangan dan pembuatan hardware Sistem ini terdiri dari perancangan mekanik dan perancangan elektronik. Perancangan mekanik yaitu membuat perancangan prototype rumah dan perancangan elektronik yaitu membuat rangkaian elektronika yang akan direalisasikan ke bentuk PCB (Printed Circuit Board).

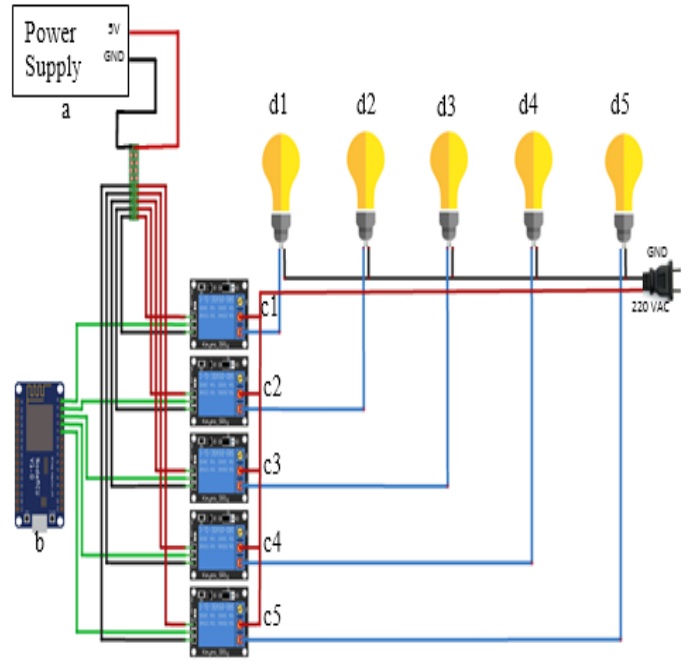

Gambar 2. Rangkaian Keseluruhan Alat

Pada penelitian ini catu daya diperlukan sebagai penyedia tegangan atau sumber daya dari peralatan elektronika yang di buat. Komponen penyusun perancangan power supply ini diantaranya Trafo stepdown, dioda, kapasitor, resistor, led indikator dan IC regulator. Rangkaian nodemcu digunakan sebagai kontroler dan komunikasi data berbasis wireless. Pin out yang digunakan pada nodemcu hanya 5 buah yaitu pin digital D0 - D4 seperti yang terlihat pada tabel 1.

Tabel 1. Pin Nodemcu Yang Digunakan

\begin{tabular}{|c|c|c|}
\hline Bagian & Pin & Kegunaan \\
\hline $\begin{array}{l}\text { Modul } \\
\text { Relay } 1\end{array}$ & D0 & $\begin{array}{l}\text { Pin D0 ini digunakan } \\
\text { sebagai output nodemcu } \\
\text { untuk ON/OFF relay dan } \\
\text { ON/OFF lampu kamar } 1\end{array}$ \\
\hline $\begin{array}{l}\text { Modul } \\
\text { Relay } 2\end{array}$ & D1 & $\begin{array}{l}\text { Pin D1 ini digunakan } \\
\text { sebagai output nodemcu } \\
\text { untuk ON/OFF relay dan } \\
\text { ON/OFF lampu kamar } 2\end{array}$ \\
\hline $\begin{array}{l}\text { Modul } \\
\text { Relay } 3\end{array}$ & D2 & $\begin{array}{l}\text { Pin D2 ini digunakan } \\
\text { sebagai output nodemcu } \\
\text { untuk ON/OFF relay dan } \\
\text { ON/OFF lampu ruang } \\
\text { tengah }\end{array}$ \\
\hline $\begin{array}{l}\text { Modul } \\
\text { Relay } 4\end{array}$ & D3 & $\begin{array}{l}\text { Pin D3 ini digunakan } \\
\text { sebagai output nodemcu } \\
\text { untuk ON/OFF relay dan } \\
\text { ON/OFF lampu dapur }\end{array}$ \\
\hline $\begin{array}{l}\text { Modul } \\
\text { Relay } 5\end{array}$ & D4 & $\begin{array}{l}\text { Pin D4 ini digunakan } \\
\text { sebagai output nodemcu } \\
\text { untuk ON/OFF relay dan } \\
\text { ON/OFF lampu teras }\end{array}$ \\
\hline
\end{tabular}

Rangkaian relay berfungsi untuk memutus dan menghubungkan rangkaian. Komponen penyusun modul relay adalah resistor, transistor, dioda, led, relay. Tabel 2 dibawah ini adalah tabel sistim kerja relay ketika output data nodemcu adalah 0 atau 1 . Tiap-tiap modul relay terhubung ke pin digital nodemcu yang berbeda. 
Tabel 2. Prinsip Kerja Relay Terhadap Kontrol Nodemcu

\begin{tabular}{ccc}
\hline \multicolumn{2}{c}{$\begin{array}{c}\text { Output data } \\
\text { nodemcu }\end{array}$} & Relay \\
\cline { 1 - 2 } 0 & 1 & Modul relay 1 ON \\
\hline D0 & & Modul relay 1 OFF \\
\hline & D0 & Modul relay 2 ON \\
\hline D1 & & Modul relay 2 OFF \\
\hline & D1 & Modul relay 3 ON \\
\hline D2 & & Modul relay 3 OFF \\
\hline & D2 & Modul relay 4 ON \\
\hline D3 & & Modul relay 4 OFF \\
\hline & D3 & Modul relay 5 ON \\
\hline D4 & & Modul relay 5 OFF \\
\hline & D4
\end{tabular}

Lampu yang digunakan pada tugas akhir ini adalah candle light 5 watt 220 Vac dan menggunakan fitting lampu berukuran r14 sebanyak 5 buah. Penggunaan fitting adalah untuk mempermudah pemasangan lampu pada setiap ruangan. Lampu pijar membutuhkan inputan 220 vac, didapatkan dari trafo yang terhubung ke com relay dan gnd lampu dihubungkan ke gnd trafo. Tabel 3 berikut ini adalah sistem kerja masing-masing lampu terhadap relay sebagai saklar. Kondisi lampu tergantung bagaimana kondisi relay.

Tabel 3. Kondisi Lampu Terhadap Relay

\begin{tabular}{|c|c|c|}
\hline Relay & $\begin{array}{l}\text { Kondisi } \\
\text { Relay }\end{array}$ & Kondisi Lampu \\
\hline \multirow{2}{*}{$\begin{array}{l}\text { Modul } \\
\text { Relay } 1\end{array}$} & ON & $\begin{array}{c}\text { Lampu Kamar } 1 \\
\text { ON }\end{array}$ \\
\hline & OFF & $\begin{array}{c}\text { Lampu Kamar } 1 \\
\text { OFF }\end{array}$ \\
\hline \multirow{2}{*}{$\begin{array}{l}\text { Modul } \\
\text { Relay } 2\end{array}$} & ON & $\begin{array}{c}\text { Lampu Kamar } 2 \\
\text { ON }\end{array}$ \\
\hline & OFF & $\begin{array}{c}\text { Lampu Kamar } 2 \\
\text { OFF }\end{array}$ \\
\hline \multirow{2}{*}{$\begin{array}{r}\text { Modul } \\
\text { Relay } 3\end{array}$} & $\mathrm{ON}$ & $\begin{array}{c}\text { Lampu Ruang } \\
\text { Tengah ON }\end{array}$ \\
\hline & OFF & $\begin{array}{c}\text { Lampu Ruang } \\
\text { Tengah OFF }\end{array}$ \\
\hline \multirow{2}{*}{$\begin{array}{r}\text { Modul } \\
\text { Relay } 4\end{array}$} & $\mathrm{ON}$ & $\begin{array}{c}\text { Lampu Dapur } \\
\text { ON }\end{array}$ \\
\hline & OFF & $\begin{array}{c}\text { Lampu Dapur } \\
\text { OFF }\end{array}$ \\
\hline \multirow{2}{*}{$\begin{array}{r}\text { Modul } \\
\text { Relay } 5\end{array}$} & $\mathrm{ON}$ & Lampu Teras ON \\
\hline & OFF & $\begin{array}{c}\text { Lampu Teras } \\
\text { OFF }\end{array}$ \\
\hline
\end{tabular}

Tabel sistem secara keseluruhan dapat dilihat pada tabel 4. Dimana pada tabel tersebut akan menampilkan cara kerja sistem secara keseluruhan.

\begin{tabular}{cclll}
\multicolumn{5}{c}{ Tabel 4. Tabel Sistem Keseluruhan } \\
\hline $\begin{array}{c}\text { Button } \\
\text { pada }\end{array}$ & Thingspeak & Relay & Lampu \\
$\begin{array}{c}\text { Smartp } \\
\text { hone }\end{array}$ & & & & \\
\hline ON1 & Grafik field1 & Modul & Lampu \\
& $=1$ & & relay 1 & kamar 1 \\
& & & ON & ON \\
\hline OFF1 & Grafik & field1 & Modul & Lampu \\
\hline
\end{tabular}

\begin{tabular}{|c|c|c|c|}
\hline & $=0$ & $\begin{array}{ll}\text { relay } & 1 \\
\text { OFF } & \\
\end{array}$ & $\begin{array}{ll}\text { kamar } & 1 \\
\text { OFF }\end{array}$ \\
\hline ON2 & $\begin{array}{l}\text { Grafik field2 } \\
=1\end{array}$ & $\begin{array}{l}\text { Modul } \\
\text { relay } 2 \\
\text { ON }\end{array}$ & $\begin{array}{l}\text { Lampu } \\
\text { kamar } 2 \\
\text { ON }\end{array}$ \\
\hline OFF2 & $\begin{array}{l}\text { Grafik field2 } \\
=0\end{array}$ & $\begin{array}{l}\text { Modul } \\
\text { relay } 2 \\
\text { OFF }\end{array}$ & $\begin{array}{l}\text { Lampu } \\
\text { kamar } 2 \\
\text { OFF }\end{array}$ \\
\hline ON3 & $\begin{array}{l}\text { Grafik field3 } \\
=1\end{array}$ & $\begin{array}{l}\text { Modul } \\
\text { relay } 3 \\
\text { ON }\end{array}$ & $\begin{array}{l}\text { Lampu } \\
\text { ruang } \\
\text { tengah } \\
\text { ON }\end{array}$ \\
\hline OFF3 & $\begin{array}{l}\text { Grafik field3 } \\
=0\end{array}$ & $\begin{array}{l}\text { Modul } \\
\text { relay } 3 \\
\text { OFF }\end{array}$ & $\begin{array}{l}\text { Lampu } \\
\text { ruang } \\
\text { tengah } \\
\text { OFF }\end{array}$ \\
\hline ON4 & $\begin{array}{l}\text { Grafik field4 } \\
=1\end{array}$ & $\begin{array}{l}\text { Modul } \\
\text { relay } 4 \\
\text { ON }\end{array}$ & $\begin{array}{l}\text { Lampu } \\
\text { dapur } \\
\text { ON }\end{array}$ \\
\hline OFF4 & $\begin{array}{l}\text { Grafik field } 4 \\
=0\end{array}$ & $\begin{array}{l}\text { Modul } \\
\text { relay } 4 \\
\text { OFF }\end{array}$ & $\begin{array}{l}\text { Lampu } \\
\text { dapur } \\
\text { OFF }\end{array}$ \\
\hline ON5 & $\begin{array}{l}\text { Grafik field5 } \\
=1\end{array}$ & $\begin{array}{l}\text { Modul } \\
\text { relay } 5 \\
\text { ON }\end{array}$ & $\begin{array}{l}\text { Lampu } \\
\text { teras ON }\end{array}$ \\
\hline OFF5 & $\begin{array}{l}\text { Grafik field5 } \\
=0\end{array}$ & $\begin{array}{l}\text { Modul } \\
\text { relay } 5 \\
\text { OFF }\end{array}$ & $\begin{array}{l}\text { Lampu } \\
\text { teras } \\
\mathrm{OFF}\end{array}$ \\
\hline
\end{tabular}

\section{Perancangan Mekanik}

Perancangan mekanik alat adalah desain alat yang akan dibuat nantinya dalam bentuk prototype. Alat yang dibuat berupa prototype sebuah rumah. Sebelum pembuatan mekanik alat terlebih dahulu membuat desain perancangannya untuk mempermudah proses pengerjaan. Prototype ini dibuat menggunakan triplek dengan tebal $9 \mathrm{~mm}$, untuk menghubungkan tiap sisi bagian digunakan paku .Ukuran panjang dari protype ini adalah $50 \mathrm{~cm}$ dengan lebar $40 \mathrm{~cm}$ dan tinggi $30 \mathrm{~cm}$. Adapun rancangan pembuatan miniature rumah atau prototype untuk penelitian ini sebagai berikut:

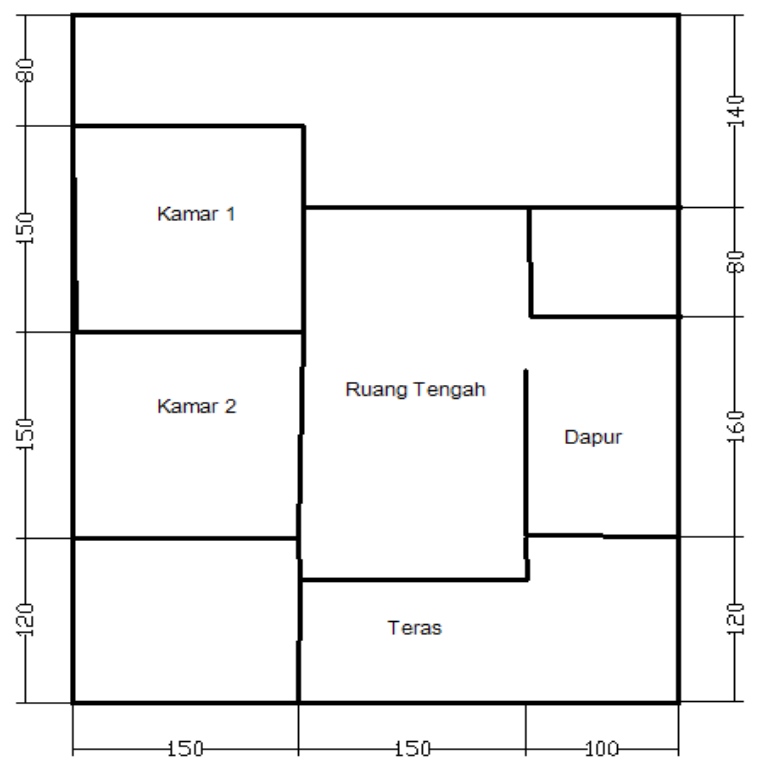

Gambar 3. Denah Rumah (ukuran dalam mm) 


\section{Perancangan Software}
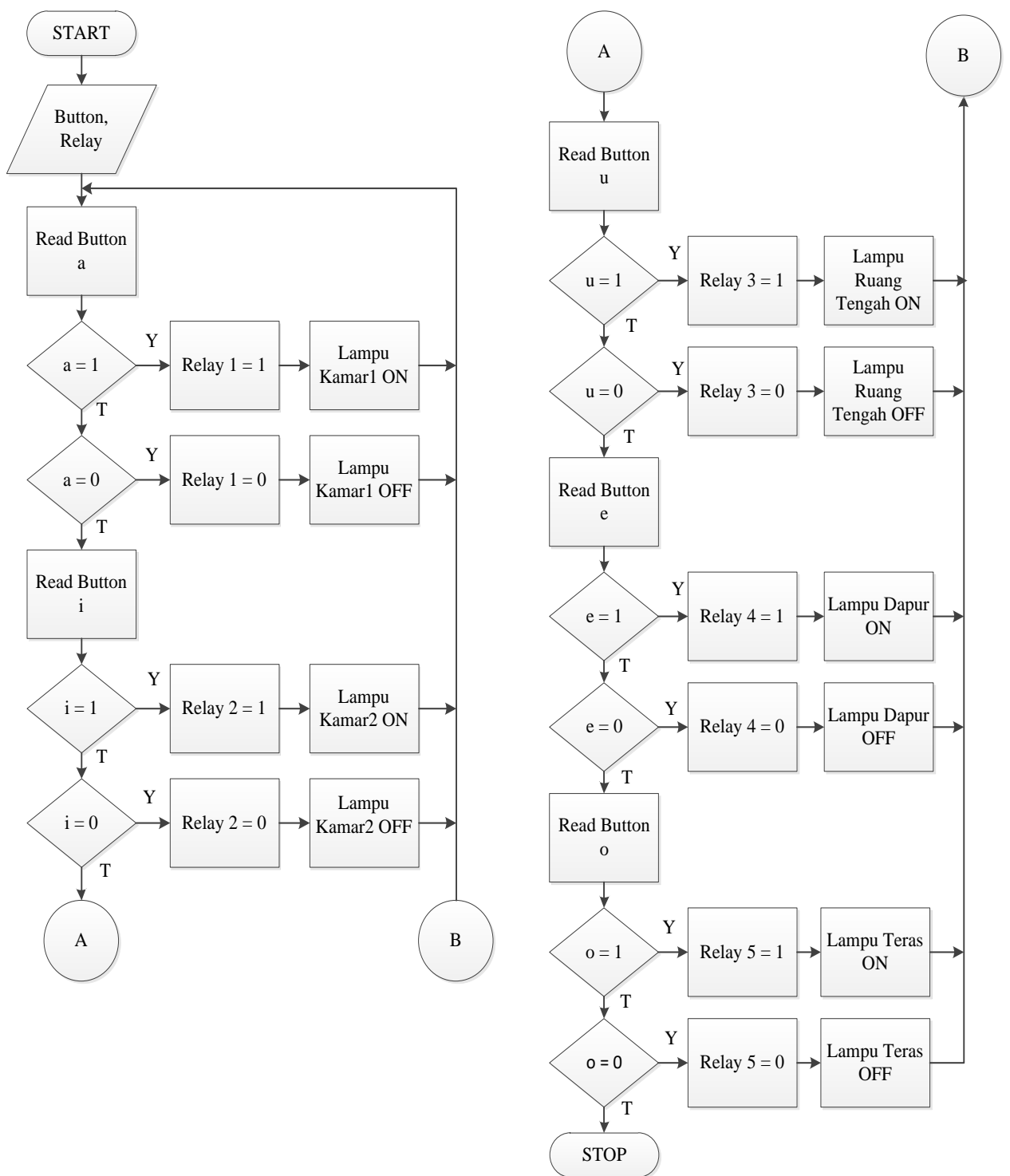

Gambar 3. Flowchart

\section{HASIL DAN PEMBAHASAN}

Pengujian ini dilakukan untuk mengetahui berapa lama waktu yang diperlukan untuk menyalakan atau mematikan satu buah lampu yang dikendalikan langsung oleh smartphone. Waktu dihitung mulai dari button pada aplikasi ditekan hingga lampu menyala atau mati dengan menggunakan stopwatch. Pembagian perhitungan waktu ada tiga yaitu pengiriman data android ke server thingspeak dan dari thingspeak ke nodemcu. Pengujian dilakukan sebanyak 2 kali yaitu pada jarak dekat dan jarak jauh untuk mengetahui pengaruh jarak pada waktu kontrol. Hasil pengujian waktu kontrol ketika jarakn dekat dapat dilihat pada tabel berikut ini.

. Tabel 5. Perhitungan Waktu Pengiriman Data Jarak Dekat

\begin{tabular}{ccccc}
\hline \multirow{2}{*}{ Lampu } & & \multicolumn{2}{c}{ Waktu (s) } & Total waktu (s) \\
\cline { 2 - 5 } & & $\begin{array}{c}\text { Android } \\
- \\
\text { Thingspe } \\
\text { ak }\end{array}$ & $\begin{array}{c}\text { Thingspeak - } \\
\text { Nodemcu }\end{array}$ & $\begin{array}{c}\text { Android - } \\
\text { Nodemcu }\end{array}$ \\
\hline \multirow{2}{*}{ Kamar1 } & ON1 & 13 & 5 & 18 \\
\cline { 2 - 5 } & OFF1 & 6 & 9 & 15 \\
\hline \multirow{2}{*}{ Kamar2 } & ON2 & 15 & 4 & 19 \\
\cline { 2 - 5 } Ruang & OFF2 & 10 & 2 & 11 \\
\cline { 2 - 5 } Tengah & ON3 & 10 & 1 & 13 \\
\hline \multirow{2}{*}{ OFF3 } & 10 & 3 &
\end{tabular}




\begin{tabular}{ccccc}
\hline \multirow{2}{*}{ Dapur } & ON4 & 8 & 2 & 10 \\
\cline { 2 - 5 } & OFF4 & 9 & 2 & 11 \\
\hline \multirow{2}{*}{ Teras } & ON5 & 13 & 2 & 15 \\
\cline { 2 - 5 } & OFF5 & 10 & 1 & 11 \\
\hline \multicolumn{2}{c}{ Rata-rata } & 10.4 & 3.1 & 13.5 \\
\hline
\end{tabular}

Sedangkan untuk hasil pengujian waktu kontrol jauh dengan aplikasi smarthpone dijakarta dan perangkat sistem prototype di padang dapat dilihat pada tabel berikut ini.

Tabel 6. Perhitungan Waktu Pengiriman Data Jarak Jauh (Jakarta-Padang)

\begin{tabular}{|c|c|c|c|c|}
\hline \multirow[b]{2}{*}{ Lampu } & & \multicolumn{2}{|c|}{ Waktu (s) } & $\begin{array}{c}\text { Total } \\
\text { waktu }\end{array}$ \\
\hline & & $\begin{array}{c}\text { Android } \\
- \\
\text { Thingspe } \\
\text { ak } \\
\end{array}$ & $\begin{array}{c}\text { Thingspea } \\
\text { k - } \\
\text { Nodemcu }\end{array}$ & $\begin{array}{c}\text { Android } \\
- \\
\text { Nodemc } \\
\text { u }\end{array}$ \\
\hline \multirow{2}{*}{ Kamar1 } & ON1 & 8 & 8 & 16 \\
\hline & OFF1 & 14 & 3 & 17 \\
\hline \multirow{2}{*}{ Kamar2 } & ON2 & 10 & 5 & 15 \\
\hline & OFF2 & 10 & 3 & 13 \\
\hline \multirow{2}{*}{ Ruang Tengah } & ON3 & 12 & 1 & 13 \\
\hline & OFF3 & 11 & 4 & 15 \\
\hline \multirow{2}{*}{ Dapur } & ON4 & 10 & 3 & 13 \\
\hline & OFF4 & 9 & 6 & 15 \\
\hline \multirow{2}{*}{ Teras } & ON5 & 11 & 1 & 12 \\
\hline & OFF5 & 8 & 1 & 9 \\
\hline \multicolumn{2}{|c|}{ Rata-rata } & 10.3 & 3.5 & 13.8 \\
\hline
\end{tabular}

Proses pengontrolan yang dilakukan ini bergantung pada kecepatan pengiriman data dari smartphone ke web server thingspeak dan juga bergantung pada sistem perangkat nodemcu dalam membaca data di server thingspeak.

\section{A. Perhitungan Rata-Rata Waktu Pengiriman Data Ketika Lampu Dikontrol Jarak Dekat}

- rata-rata waktu pada android-thingspeak.

$$
\begin{aligned}
& \text { Rat }=\frac{13 s+6 s+15 s+10 s+10 s+10 s+8 s+9 s+13 s+10 s}{10} \\
& \text { Rat }=\frac{104}{10} \\
& \text { Rat }=10.4 s
\end{aligned}
$$

- rata-rata waktu pada thingspeak-nodemcu.

$$
\begin{aligned}
R t n & =\frac{5 s+9 s+4 s+2 s+1 s+3 s+2 s+2 s+2 s+1 s}{10} \\
\text { Rtn } & =\frac{31}{10} \\
\text { Rtn } & =3.1 s
\end{aligned}
$$

- rata-rata waktu total android-nodemcu.

$$
\begin{aligned}
& \text { Ran }=\frac{18 s+15 s+19 s+12 s+11 s+13 s+10 s+11 s+15 s+11 s}{10} \\
& \text { Ran }=\frac{135}{10} \\
& \text { Ran }=13.5 s
\end{aligned}
$$

Dari data yang diperoleh menunjukkan bahwa waktu pengiriman data pada setiap lampu dari smartphone ke thingspeak relatif lebih lama dibandingkan waktu pembacaan data thingspeak oleh nodemcu. Rata- rata waktu yang diperoleh dari perhitungan diatas juga menunjukan bahwa waktu pengiriman data smartphone ke thingspeak lebih lama daripada pembacaan data thingspeak oleh nodemcu. Hal ini disebabkan oleh koneksi jaringan pada smartphone lebih buruk daripada koneksi jaringan nodemcu. Rata-rata waktu kontrol lampu secara keseluruhan dari button ditekan hingga lampu menyala atau mati adalah $13.5 \mathrm{~s}$. Waktu paling cepat adalah $10 \mathrm{~s}$ dan paling lama adalah 19 s.

B.Perhitungan rata-rata waktu pengiriman data ketika lampu dikontrol jarak jauh

- rata-rata waktu pada android-thingspeak.

$R a t=\frac{8 s+14 s+10 s+10 s+12 s+11 s+10 s+9 s+11 s+8 s}{10}$

Rat $=\frac{103}{10}$

Rat $=10.3 s$

- rata-rata waktu pada thingspeak-nodemcu.

$R t n=\frac{8 s+3 s+5 s+3 s+1 s+4 s+3 s+6 s+1 s+1 s}{10}$

$\operatorname{Rtn}=\frac{35}{10}$

$\operatorname{Rtn}=3.5 \mathrm{~s}$

- rata-rata waktu total android-nodemcu.

$$
\begin{aligned}
\text { Ran } & =\frac{16 s+17 s+15 s+13 s+13 s+15 s+13 s+15 s+12 s+9 s}{10} \\
\text { Ran } & =\frac{138}{10} \\
\text { Ran } & =13.8 s
\end{aligned}
$$

Dari data yang diperoleh menunjukkan bahwa waktu pengiriman data pada setiap lampu dari smartphone ke thingspeak relatif lebih lama dibandingkan waktu pembacaan data thingspeak oleh nodemcu. Rata- rata waktu yang diperoleh dari 
perhitungan diatas juga menunjukan bahwa waktu pengiriman data smartphone ke thingspeak lebih lama daripada pembacaan data thingspeak oleh nodemcu. Hal ini disebabkan oleh koneksi jaringan pada smartphone lebih buruk daripada koneksi jaringan nodemcu.

Rata-rata waktu kontrol lampu secara keseluruhan dari button ditekan hingga lampu menyala atau mati adalah 13.8 s. Waktu paling cepat adalah $9 \mathrm{~s}$ dan paling lama adalah $17 \mathrm{~s}$. Hasil perhitungan rata-rata waktu pada kontrol jarak dekat dan jauh memiliki nilai yang tidak jauh berbeda. Maka dapat dikatakan bahwa jarak tidak mempengaruihi waktu kontrol. Yang mempengaruhi waktu kontrol adalah koneksi jaringan pada smartphone dan nodemcu.

\section{KESIMPULAN}

Ada beberapa kesimpulan yang didapat dari perncangan dan pengujian perangkat kontrol lampu, diantaranya sebagai berikut :

1. Perangkat kontrol lampu yang dibuat mampu bekerja dengan baik saat dilakukan pengontrolan menggunakan smartphone android melalui jaringan pada jaringan internet baik secara jarak dekat maupun jarak jauh.

2. Berdasarkan hasil pengujian yang dilakukan waktu rata-rata pengontrolan lampu jarak dekat adalah $13.5 \mathrm{~s}$ dan waktu rata-rata pengontrolan lampu jarak jauh adalah $13.8 \mathrm{~s}$.

3. Jarak pengontrolan lampu tidak mempengaruhi waktu pengiriman data dari smartphone hingga lampu menyala atau mati.

4. Pengontrolan perangkat kontrol lampu bergantung pada kecepatan jaringan internet smartphone juga kecepatan pengambilan data pada sistem perangkat kontrol lampu itu sendiri.

\section{REFERENSI}

[1] Danny Kurnianto, Abdul Mujib Hadi, Eka Wahyudi. 2016. Perancangan Sistem Kendali Otomatis Pada Smart Home Menggunakan Modul Arduino Uno. JNTE Vol: 5, No. 2, Juli 2016. Hal 260-270

[2] I. Dinata and W. Sunanda, "Implementasi Wireless Monitoring Energi Listrik Berbasis Web Database," JNTE, vol. 4, no. 1 , pp. 83-88, 2015

[3] Firdaus, A. A. Nuryono, and A. Sahroni, "Monitoring dan Kendali Lampu Berbasis Jaringan WiFi untuk Mendukung
Smart Home," in Seminar Nasional ke - 9: Rekayasa Teknologi Industri dan Informasi, pp. 51-58.

[4] A. S. Rafika, M. S. H. Putra, and W. Larasati, "Smart Home Automatic Menggunakan Media Bluetooth Berbasis Mikrokontroller Atmega 328," CCIT, vol. 8, no. 3, pp. 215-222, 2015 .

[5] Himanshu Verma ; Madhu Jain ; Khushhali Goel ; Aditya Vikram ; Gaurav Verma. 2016. Smart home system based on Internet of Things. 2016 3rd International Conference on Computing for Sustainable Global Development (INDIACom). India

[6] Irina-Ioana Pătru ; Mihai Carabaș ; Mihai Bărbulescu ; Laura Gheorghe. 2016. Smart home IoT system. 2016 15th RoEduNet Conference: Networking in Education and Research. Romania

[7] Ellian Adhi Satya, Yuli Christiyono, \& Maman Somantri. 2016. Pengontrolan Lampu Melalui Internet Menggunakan Mikrokontroler Arduino Berbasis Android. Universitas Diponegoro Semarang.

[8] Immanuel Warangkiran, Kaunang, Arie S.M Lumenta \& Arthur M.Rumagit. 2014. Perancangan Kendali Lampu Berbasis Android. UNSRAT, Manando.

[9] Andri Saputra, Dwi Febriansyah, \& Haris Kuswara. 2014. Alat Kendali Lampu Rumah Menggunakan Bluetooth Berbasis Android. STMIK PalContech.

[10] Anton, Yuliarman, \& Tuti Angraini. 2016. Pengendalian Beban Generator PLTMH Berbasis Mikrokontroler. National Conference of Applied Sciences, Engineering, Business and Information Technology. Politeknik Negeri Padang. 